\title{
Poly(ester amide) nanocomposites by in situ polymerization: Kinetic studies on polycondensation and crystallization
}

\author{
L. Morales-Gámez ${ }^{1,2}$, I. Jones ${ }^{1}$, L. Franco ${ }^{1,2}$, J. Puiggali $^{1,2 *}$ \\ ${ }^{1}$ Departament d'Enginyeria Química, Universitat Politècnica de Catalunya, Av. Diagonal 647, E-08028, Barcelona, Spain \\ ${ }^{2}$ Centre de Recerca en NanoEnginyeria (CRNE), Universitat Politècnica de Catalunya, Edifici C', c/ Pascual i Vila s/n, \\ E-08028, Barcelona, Spain
}

Received 16 December 2011; accepted in revised form 28 February 2011

\begin{abstract}
Preparation of nanocomposites by in situ polymerization of sodium chloroacetylaminohexanoate in the presence of Cloisite 20A (C20A) or Cloisite 30B (C30B) organo-modified montmorillonites was studied. Both clays rendered an intercalated structure that contrasts with the exfoliated structure previously found with the use of the C25A montmorillonite. Polymerization under non-isothermal and isothermal conditions was evaluated by Wide Angle X-ray Diffraction (WAXD) synchrotron radiation and Fourier Transform Infrared Spectroscopy (FTIR) experiments. Results indicate that $\mathrm{C} 20 \mathrm{~A}$ and $\mathrm{C} 30 \mathrm{~B}$ had a similar influence on the polymerization kinetics. Thus, the activation energy and the Arrhenius preexponential factor decreased compared to those calculated for the neat monomer. Clear differences were also found when using the $\mathrm{C} 25 \mathrm{~A}$ clay since, in this case, polymerization had similar activation energy to that determined for the neat monomer. The crystallization kinetics of the intercalated C20A and C30B nanocomposites was studied by FTIR and optical microscopy. The incorporation of clay particles increased the overall rate kinetic constant due to the enhancement of the primary nucleation. On the contrary, the spherulitic growth rate was slightly disfavored by the clay.
\end{abstract}

Keywords: nanocomposites, in situ polymerization, poly(ester amide), polymerization kinetics, crystallization kinetics

\section{Introduction}

The preparation of new polymer nanocomposites is a promising topic since material properties can be enhanced and their range of applications extended by using molecular or nanoscale reinforcements rather than conventional fillers [1-5]. Since the first works performed with nylon $6[6,7]$, several polymer based systems and preparation methodologies such as melt-mixing, solution intercalation and in situ polymerization have been developed. Results clearly demonstrate that properties of the neat polymer like water-absorption rate, thermal-expansion coefficients, Young modulus, thermal stability and gas barrier effect can be improved by the incorpora- tion of a small amount of clay, and also that the crystallization kinetics can be affected.

Layered silicate particles are especially interesting for nanocomposite preparation as they may be dispersed into individual layers with a thickness close to $1 \mathrm{~nm}$ to tune surface interactions with the polymer/monomer through exchange reactions with organic and inorganic cations [8]. The final structure of the composite depends on the extent to which the organic matrix and inorganic clay components are made compatible [9], and varies from an intercalated to a fully exfoliated nanostructure, which has an obvious impact on the final properties. Despite extensive research, the influence of nano-

\footnotetext{
${ }^{*}$ Corresponding author, e-mail: Jordi.Puiggali@upc.es
}

(c) BME-PT 
composite structure on nucleation and crystal growth rate is not entirely clear in view of the conflicting results reported in some cases [10-14].

Aliphatic poly(ester amide)s constitute a promising family of materials since the presence of hydrolyzable ester groups may enhance degradability, and the establishment of intermolecular hydrogen bonding interactions between amide groups may provide suitable thermal and mechanical properties for most applications [15-19]. Furthermore, several monomers and synthetic routes have been developed to obtain materials with variable composition and chemical microstructure, which can consequently meet numerous requirements. The alternating poly(ester amide) derived from glycolic acid and 6-aminohexanoic acid (poly(glc-alt-amh)) has recently received attention for two main reasons: a) The simple synthesis procedure based on only two reaction steps (Figure 1a), and b) A composition based on the main units of biodegradable polyesters (glycolic acid) and aliphatic polyamides (6-aminohexanoic acid).

Poly(glc-alt-amh)) is obtained by a thermal polycondensation reaction based on the formation of a metal halide salt as the driving force of the condensation reaction [20,21], which seems an appropriate procedure to prepare nanocomposites by in situ polymerization. This is a highly attractive technique due to its versatility and compatibility with various reactive monomers, making it a valuable process for commercial applications [22, 23]. Several examples in the literature concern the preparation of polystyrene [24], polycaprolactone [25] and nylon 6 [26] nanocomposites.

The in situ polymerization technique was effective and rendered practically exfoliated nanocomposites of poly(glc-alt-amh) and the Cloisite 25A (C25A) organo-modified montmorillonite [27]. Typical calorimetric techniques were not suitable for proper evaluation of the polymerization kinetics at temperatures lower than $145^{\circ} \mathrm{C}$ due to the overlapping of the exothermic polymerization peak with an endothermic peak associated with polymer crystallization. Thus, Fourier Transform Infrared Spectroscopy (FTIR) was a basic tool to compare and study the influence of clay particles on the polymerization kinetics. Nanocomposites prepared by the above in situ polymerization and the melt mixing technique gave rise to two different structures (i.e. exfoliated

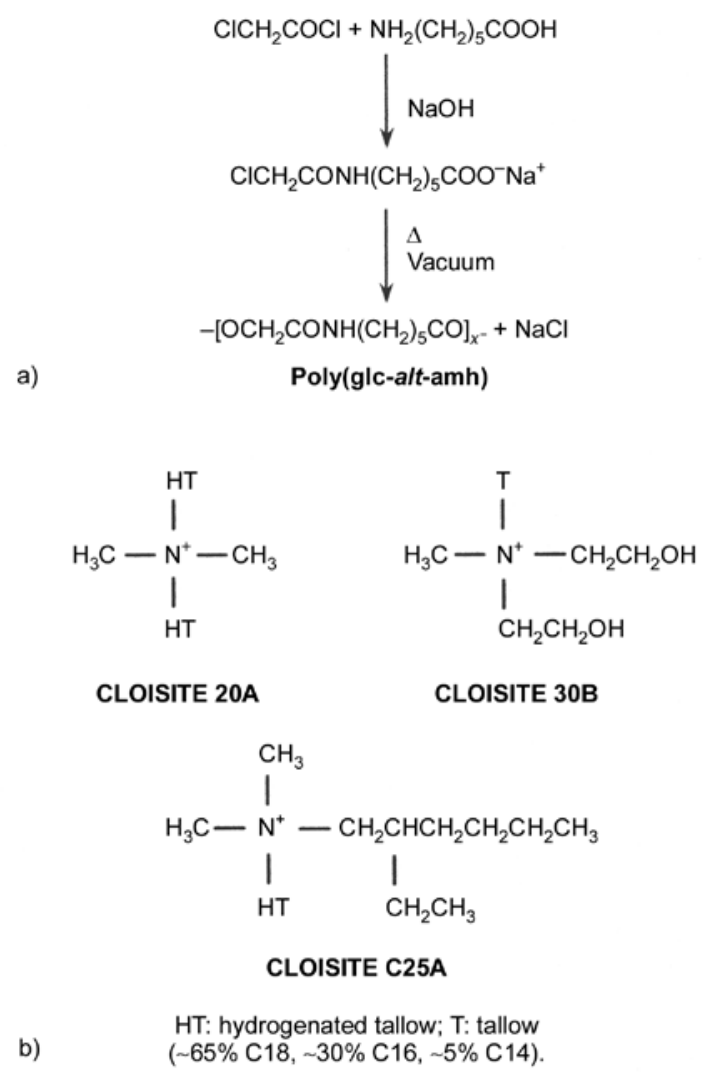

Figure 1. a) Synthesis scheme for the poly(ester amide) studied in this work. b) Chemical structure of Closites 20A, 25A and 30B

and intercalated) that clearly influenced the crystallization kinetics [27, 28]. The main purpose of the present work is to determine the effect of montmorillonites based on two different surfactants (Closites 30B and 20A) on in situ polymerization and to study the crystallization kinetics of the derived nanocomposites. The polymerization kinetics is evaluated through real-time synchrotron and FTIR experiments whereas the crystallization kinetics is studied through FTIR to obtain the overall crystallization rate and optical microscopy measurements to determine the nucleation and crystal growth rates.

\section{Experimental section}

\subsection{Materials}

The monomer, sodium chloroacetylaminohexanoate, was synthesized following a previously reported method [20, 21]. All reagents and solvents were purchased from Aldrich Chemical Company, (Milwaukee, WI, USA) and used as received. Polymerization was based on a thermal polycondensation which rendered sodium chloride as a byproduct (Figure 1a) [20, 21]. 
The nanocomposites were based on two organomodified layered phyllosilicates: methyl tallow bis(2-hydroxyethyl) ammonium montmorillonite (Closite 30B, Southern Clay Products, MT2EH, Gonzales, Texas, USA) and dimethyl dihydrogenated-tallow ammonium montmorillonite (Closite 20A, Southern Clay Products, 2MH2HT, Gonzales, Texas, USA). Results are also compared with those previously obtained with Closite 25 A (Southern Clay Products, 2MHTEX, Gonzales, Texas, USA) [27]. The chemical structure of all employed montmorillonite surfactants is shown in Figure 1b.

\subsection{Preparation of nanocomposites}

For both nanocomposite preparations, $10 \mathrm{mg}$ of monomer was dissolved in $10 \mathrm{ml}$ of water, and separately, the appropriate clay was dispersed in water $(<0.1 \mathrm{wt} \%)$. The monomer solution and clay dispersion were stirred for two hours, and then mixed and liophilized. The ratio of the solution and dispersion was conveniently adjusted to obtain a clay content of $3 \mathrm{wt} \%$ in the final solid. Polymerization was carried out by heating the monomer/clay mixture to $160^{\circ} \mathrm{C}$. A white solid was recovered and extensively washed with water, methanol and acetone. This procedure was similar to that performed with Cloisite 25A. For comparison purposes, polymerization without organoclay was also performed and the final sample purified as above.

No significant differences were found between the molecular weights of the neat poly(ester amide), the two new prepared nanocomposites and that derived from C25A. Thus, weight average molecular weight $\left(M_{\mathrm{w}}\right)$ and number average molecular weight $\left(M_{\mathrm{n}}\right)$ were always in the $14000-17000$ and 37000 43000 ranges, respectively, according to Gel Permeation Chromatography (GPC) measurements using 1,1,1,3,3,3-hexafluoroisopropanol as the solvent and poly(methyl methacrylate) standards.

\subsection{Measurements}

Interlayer spacing of the clay was studied by Wide Angle X-ray Diffraction (WAXD) using a Siemens D-500 diffractometer (Karlsruhe, Germany) with $\mathrm{Cu} \mathrm{K}$ radiation $(\lambda=0.1542 \mathrm{~nm})$.

The structure and distribution of Cloisite were observed with a Philips TECNAI 10 (FEI/Philips Electron Optics, Eindhoven, Netherlands) transmission electron microscope (TEM) at an accelerating voltage of $100 \mathrm{kV}$. TEM specimens were prepared by embedding in a low viscosity modified Spurr epoxy resin and curing at $40^{\circ} \mathrm{C}$ for a few days and then at $60^{\circ} \mathrm{C}$ for $6 \mathrm{~h}$. Ultrathin sections (less than $100 \mathrm{~nm}$ ) were cut at room temperature using a Sorvall Porter-Blum microtome (Sorvall Products, Newton, CT, USA) equipped with a diamond knife. Finally, the sections were collected in a trough filled with water and lifted onto carbon coated copper grids. In order to prevent diffusion of the epoxy resin into the polymer film, a thin layer of carbon was evaporated over the film surface.

The spherulitic growth rate was determined by optical microscopy using a Zeiss Axioskop 40 Pol light polarizing microscope (Carl Zeiss Microlmaging, $\mathrm{GmbH}$, Germany) equipped with a Linkam temperature control system configured by a THMS 600 heating and freezing stage (Linkam, Scientific Instruments, Guilford Surrey, United Kingdom) connected to a Liquid Nitrogen Pump (LNP 94). Spherulites were grown from homogeneous meltcrystallized thin films produced by melting $1 \mathrm{mg}$ of the polymer mixture on microscope slides. Next, small sections of these films were pressed or smeared between two cover slides and inserted in the hot stage. The thicknesses of the squeezed samples were close to $10 \mu \mathrm{m}$ in all cases. Samples were kept at $170^{\circ} \mathrm{C}$ (more than $10^{\circ} \mathrm{C}$ above the polymer melting point of $157^{\circ} \mathrm{C}$ ) for 5 minutes to wipe out sample history effects, and then quickly cooled to the selected crystallization temperature. The radius of the growing spherulites was monitored during crystallization by taking micrographs with a Zeiss AxiosCam MRC5 digital camera (Carl Zeiss Microlmaging, $\mathrm{GmbH}$, Germany) at appropriate time intervals. A first-order red tint plate was employed to determine the sign of spherulite birefringence under crossed polarizers.

Time-resolved WAXD experiments were carried out at the Collaborating Research Group (CRG) beamline BM16 of the European Synchrotron Radiation Facility (ESRF) of Grenoble. The beam was monochromatized to a wavelength of $0.098 \mathrm{~nm}$. Monomer/clay samples were confined between Kapton films and then held in a Linkam hot stage with temperature control within $0.1^{\circ} \mathrm{C}$. WAXD profiles were acquired during polymerization and crystallization experiments in time frames of $12 \mathrm{~s}$. The WAXD detector was calibrated with diffractions of 
a standard of an alumina $\left(\mathrm{Al}_{2} \mathrm{O}_{3}\right)$ sample. The diffraction profiles were normalized to the beam intensity and corrected considering the empty sample background. Deconvolution of WAXD peaks was performed with the PeakFit v4 program by Jandel Scientific Software using a mathematical function known as 'Gaussian area'.

Infrared absorption spectra were recorded with a Fourier Transform FTIR 4100 Jasco spectrometer (Jasco International Co. Ltd., Tokyo, Japan) in the $4000-600 \mathrm{~cm}^{-1}$ range. A Specac model MKII Golden Gate attenuated total reflection (ATR) with a heated Diamond ATR Top-Plate which can be used up to $200^{\circ} \mathrm{C}$, and a Series 4000 High Stability Temperature Controller were also utilized.

\section{Results and discussion}

\subsection{Dispersion structure of $\mathrm{C20A}$ and $\mathrm{C} 30 \mathrm{~B}$ clays in the poly(glc-alt-amh) composites}

C20A and C30B organo-modified clays were easily mixed with the sodium salt of $\mathrm{N}$-chloroacetyl-6aminohexanoic acid before performing thermal polycondensation at a temperature close to $160^{\circ} \mathrm{C}$. The final nanostructures were analyzed by X-ray diffraction and transmission electron microscopy. Evidence of intercalation of polymer chains into the silicate galleries can be obtained from diffraction patterns in the range of $2 \theta=1-10^{\circ}$, when the characteristic silicate diffraction peaks appear at larger spacings than neat clay ones. Similarly, the absence of these peaks may suggest an exfoliated structure. Direct TEM morphological observation is always

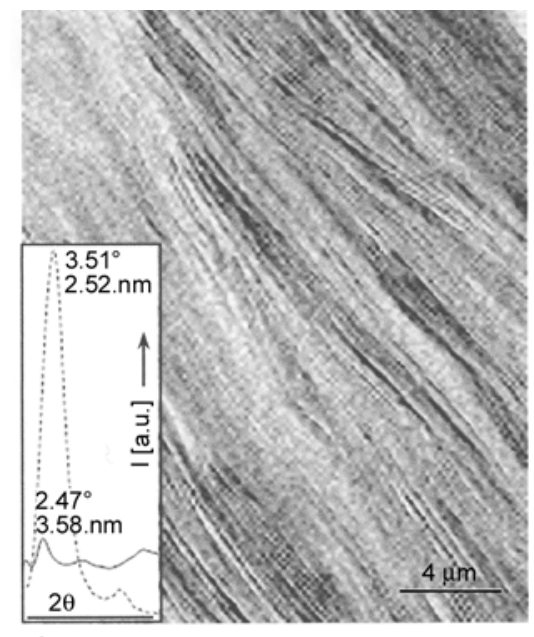

a) advisable to corroborate diffraction data although TEM images show a local distribution that also depends on how the sample was previously cut.

Direct observation of the morphology and phase distribution of ultrathin sections of poly(glc-alt$\mathrm{amh} / \mathrm{C} 20 \mathrm{~A}$ specimens by transmission electron microscopy clearly showed that an intercalated structure was predominant (Figure 2a). X-ray diffraction profiles of the nanocomposite sample also revealed the existence of a low angle reflection associated with the stacking of silicate layers. The measured spacing was close to $3.58 \mathrm{~nm}$, a higher value than that observed in the profile of C20A clay $(2.52 \mathrm{~nm})$. Thus, polymer chains in the nanocomposite sample were intercalated in the galleries of the dispersed clay and increased the interlayer spacing.

The poly(glc-alt-amh)/C30B nanocomposite showed that the 001 peak was significantly reduced and also shifted to a larger spacing (from 1.80 to $2.89 \mathrm{~nm}$ ). A certain ratio of an exfoliated structure after polymerization seems to be produced. However, it should be noticed that this feature is only supported by the great decrease of the silicate reflection and a certain loose of the layer stacking order as shown in the electron micrograph of Figure 2b. Despite the final structure could be considered intercalated, a less regular layer disposition than poly(glc-alt-amh)/C20A samples was found.

Similar observations performed with Cloisite 25A indicated a well distinguished exfoliated structure from both X-ray and TEM observations. Thus, it

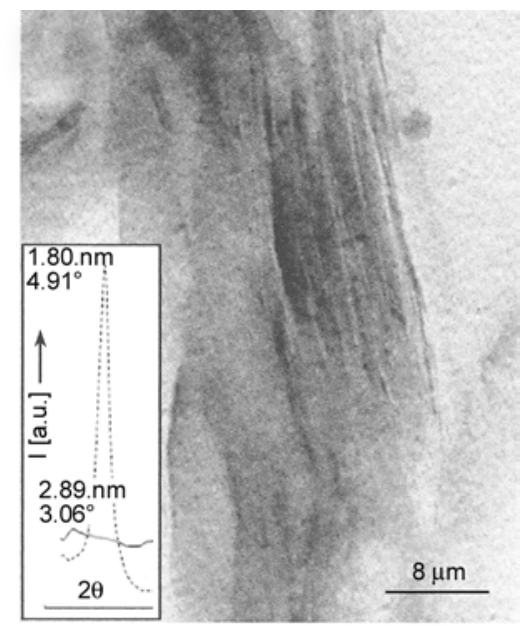

b)

Figure 2. Transmission electron micrographs showing the morphology of the poly(glc-alt-amh)/C20A (a) and poly(glc-alt$\mathrm{amh} / \mathrm{C} 30 \mathrm{~B}$ nanocomposites with a Cloisite concentration of 3\%. Inset shows the diffraction peak associated with the interlayer spacing observed in the pure organo-modified clay (solid line) and the corresponding nanocomposite sample (dashed line). 
became interesting to progress in polymerization and crystallization kinetics of new mixtures to get an insight into the effect of nanocomposite structure.

It is clear from the given experiments that monomer salts would be intercalated into the silicate galleries due to the good interactions with the cationic surfactants. Polycondensation reaction depends basically on the closeness between reactive groups (from monomer salts or the growing polymer chains) and should take place independently of the presence of quaternary ammonium cations of the organomodifier. However, the surfactant is important since influences the spacing between silicate layers (i.e. the available space for polymer chains to growth inside the silicate galleries) and also on the interactions with the growing polymer. Cloisite 20B has the largest interlayer spacing and consequently the disruption of the layer stacking to render an exfoliated nanocomposite structure may be more difficult. Experimental results suggest that the expected good interactions between the carbonyl groups of the monomer/polymer and the two hydroxyl groups of the organo-modifier may still keep a close to intercalated nanocomposite structure despite the decrease on the silicate spacing. This feature cannot be considered when Closite C25A was employed and the structure of the nanocomposite became clearly exfoliated.

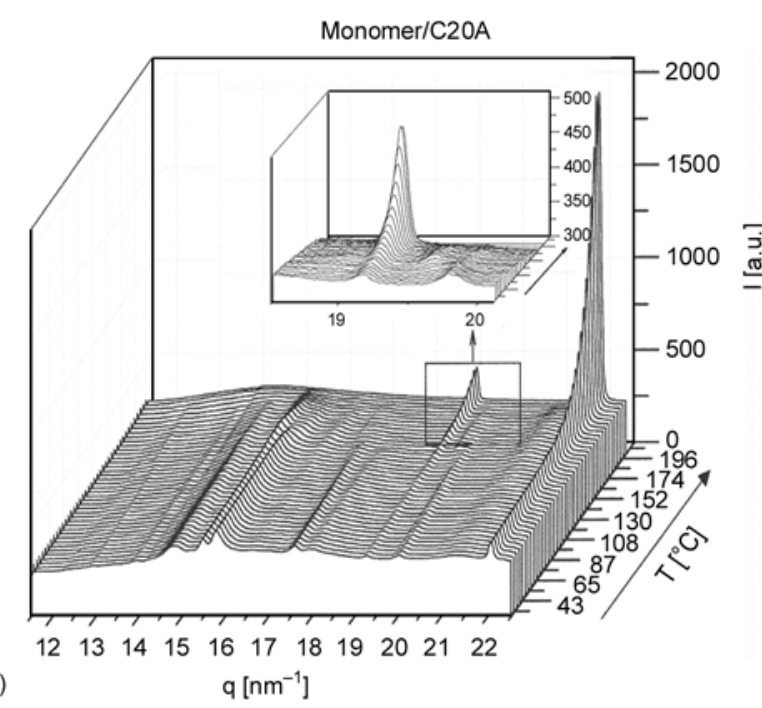

\subsection{Non-isothermal polymerization of the sodium salt of $\mathbf{N}$-chloroacetyl-6- aminohexanoic acid with $\mathrm{C20A}$ and $\mathrm{C30B}$ organo-modified clays}

Synchrotron experiments were performed to compare the non-isothermal polymerizations of the monomer mixtures with each of the considered clays. The diffraction profiles initially showed the characteristic Bragg reflections of the monomer, which were most intense at values of the scattering vector, $q=(4 \pi / \lambda) \cdot \sin \theta$, in the $14-17 \mathrm{~nm}^{-1}$ range (Figure 3). At a temperature close to $130^{\circ} \mathrm{C}$ the monomer underwent a structural change, as evidenced by the variation in intensities and spacings of the main reflections (Figure 4). Note that the intensities of reflections close to 15.4 and $15.7 \mathrm{~nm}^{-1}$ increased and slightly decreased, respectively. The intensity increase is relevant since the occurrence of polycondensation reactions should lead to the destruction of the monomer crystal structure, and consequently to a gradual disappearance of all corresponding reflections.

At temperatures higher than $150^{\circ} \mathrm{C}$, the X-ray diffraction profiles showed the appearance of two peaks at $q \sim 19$ and $22 \mathrm{~nm}^{-1}$ of gradually increasing intensity (Figure 3). These, which could be indexed as the (100) and (110) reflections of the $\mathrm{NaCl}$ structure $(\sim 0.326$ and $0.282 \mathrm{~nm}$, respectively), demonstrated the occurrence of the polycondensation

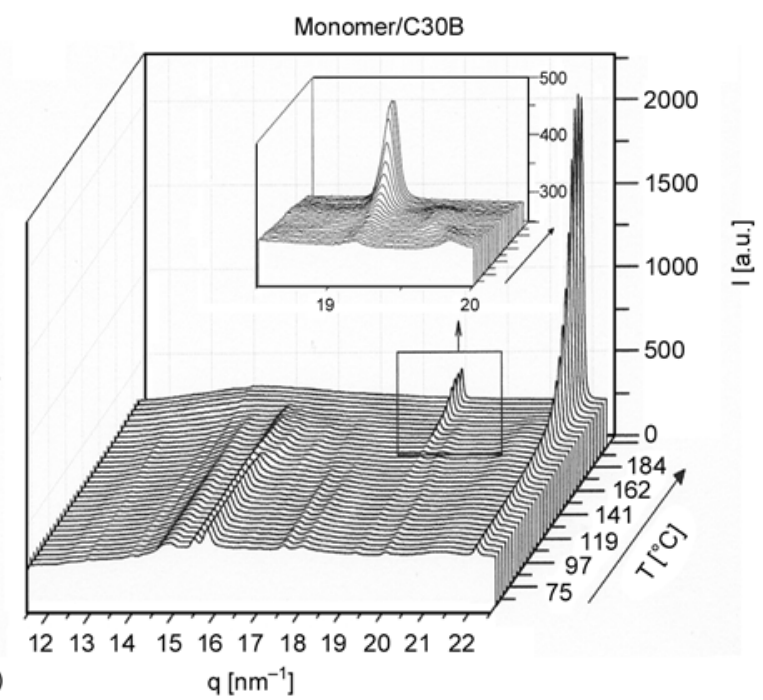

Figure 3. WAXD profiles taken during the non-isothermal polymerization performed at a heating rate of $20^{\circ} \mathrm{C} / \mathrm{min}$ with the monomer / C20A mixture (a) and the monomer / C30B mixture (b). Insets show the evolution of the weak (100) $\mathrm{NaCl}$ reflection. 
reaction. Note that a delay between polymerization and formation of the inorganic salt crystal may occur since ions must move towards the growing crystal.

The evolution of $\mathrm{NaCl}$ peak intensities is useful to follow the polymerization process and even to demonstrate that polycondensation started in the solid state. It is worth pointing out that reflections related to the monomer structure were still visible when $\mathrm{NaCl}$ peaks developed. Logically these reflections became weaker when $\mathrm{NaCl}$ peaks started to increase and disappeared completely before these peaks reached maximum intensity. Diffraction profiles clearly revealed that the polymer was not able to crystallize under the assayed non-isothermal conditions since some of its characteristic reflections [29] were not detected. The polymer structure is defined by an orthorhombic unit cell having $a=$ $0.477 \mathrm{~nm}, b=0.873 \mathrm{~nm}$ and $c=1.057 \mathrm{~nm}$ and the corresponding diffraction pattern is characterized by strong Bragg reflections in the $14.4-16.2 \mathrm{~nm}^{-1}$ range. Specifically, the (020), (101), (110) and (111) reflections that appeared at $0.437,0.435,0.418$ and

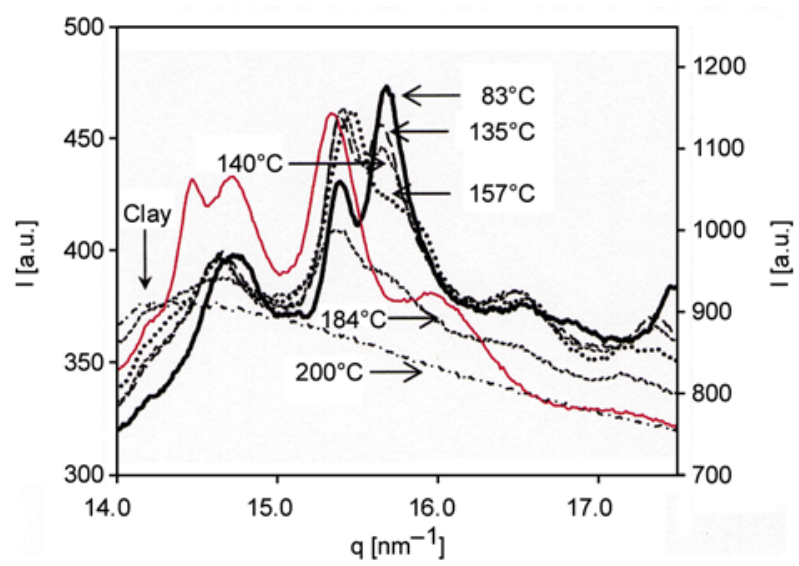

Figure 4. Representative WAXD profiles taken during a non-isothermal heating run $\left(20^{\circ} \mathrm{C} / \mathrm{min}\right)$ performed with the monomer / C20A mixture and plotted in the $q$ range where the main monomer reflections appeared $\left(14-17.5 \mathrm{~nm}^{-1}\right)$. The selected temperatures correspond to the sample before (e.g. $\left.83^{\circ} \mathrm{C}\right)$ and after (e.g. $\left.135^{\circ} \mathrm{C}\right)$ occurrence of the monomer polymorphic transition, after being partially polymerized (e.g. 140,157 and $184^{\circ} \mathrm{C}$ ) and at the end of the polycondensation reaction (e.g. $200^{\circ} \mathrm{C}$ ). In the last case only the amorphous halo and a small peak (see arrow) attributed to the clay could be observed. For the sake of completeness, the profile corresponding to a melt crystallized polymer sample taken at $140^{\circ} \mathrm{C}$ is also shown (red curve).
$0.389 \mathrm{~nm}$. At high temperature $\left(190-200^{\circ} \mathrm{C}\right)$ only an amorphous halo, the $\mathrm{NaCl}$ reflections and even small peaks attributed to $(h k 0)$ reflections of the clay were observed.

Figure 5 plots the area of the $(100) \mathrm{NaCl}$ peak versus temperature for the two studied polymerizations. A similar evolution was observed but, remarkably, some differences were detected, indicating that clay type has some influence on the polymerization kinetics. Specifically, the polymerization induction time was shorter when C20A clay was employed (i.e. the peak started to develop at temperatures of 110 and $140^{\circ} \mathrm{C}$ for $\mathrm{C} 20 \mathrm{~A}$ and $\mathrm{C} 30 \mathrm{~B}$,

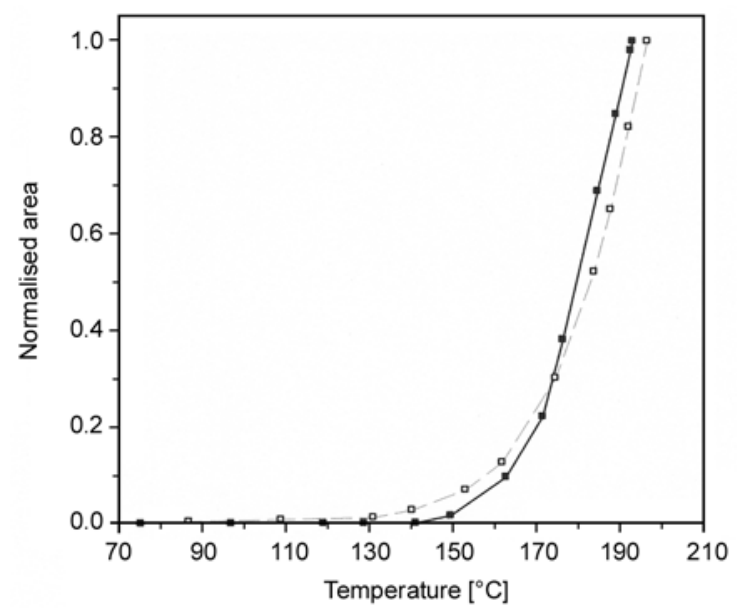

Figure 5. Intensity evolution of the (100) Bragg reflection of the $\mathrm{NaCl}$ structure $(\sim 0.326 \mathrm{~nm})$ during nonisothermal polymerization $\left(20^{\circ} \mathrm{C} / \mathrm{min}\right)$ of the monomer / C20A ( $\square$ ) and monomer / C30B (匹) mixtures

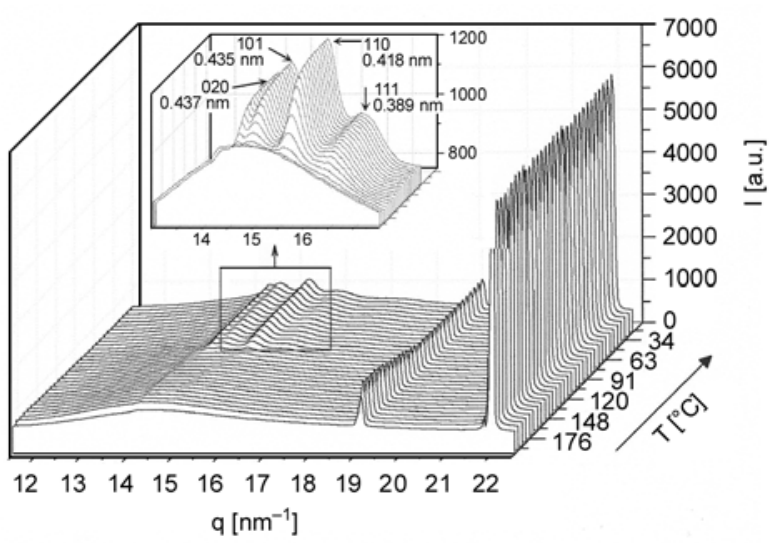

Figure 6. WAXD profiles taken during the non-isothermal crystallization performed at a cooling rate of $20^{\circ} \mathrm{C} / \mathrm{min}$ and after non-isothermal polymerization of the momomer/C20A mixture at a heating rate of $20^{\circ} \mathrm{C} / \mathrm{min}$. Insets show a magnification of the Bragg reflections corresponding to the poly (glc-alt-amh) structure 
respectively) whereas the reaction proceeded more rapidly when $\mathrm{C} 30 \mathrm{~B}$ was used (i.e. the peak developed in the $140-193$ and $110-196^{\circ} \mathrm{C}$ ranges for C20A and C30B, respectively).

$\mathrm{X}$-ray diffraction patterns taken during a subsequent cooling run (e.g. Figure 6) revealed that polymerizations were successful since the mentioned characteristic diffraction peaks of poly(glc-alt-amh) [29] appeared and progressively increased in intensity. Logically, the intensity of $\mathrm{NaCl}$ peaks remained constant during the cooling run.

\subsection{Isothermal kinetic analysis of in situ polymerization of $\mathrm{C2OA}$ and $\mathrm{C} 30 \mathrm{~B}$ clay mixtures with \\ $\mathrm{N}$-chloroacetyl-6-aminohexanoic acid}

The occurrence of the above monomer polymorphic transition and polymer crystallization should have endothermic/exothermic effects that make it impossible to evaluate the isothermal polymerization kinetics by DSC experiments. Note that these should only measure the exothermic enthalpy associated with the polycondensation reaction, which, in the studied case, is not possible due to the overlapping with the above processes. Thus, FTIR spectroscopy seems an ideal alternative technique given that the polymerization rate can be determined from the absorbance evolution of the new bonds that are formed.

The main changes in the FTIR spectra occurring during polymerization correspond to the appear-

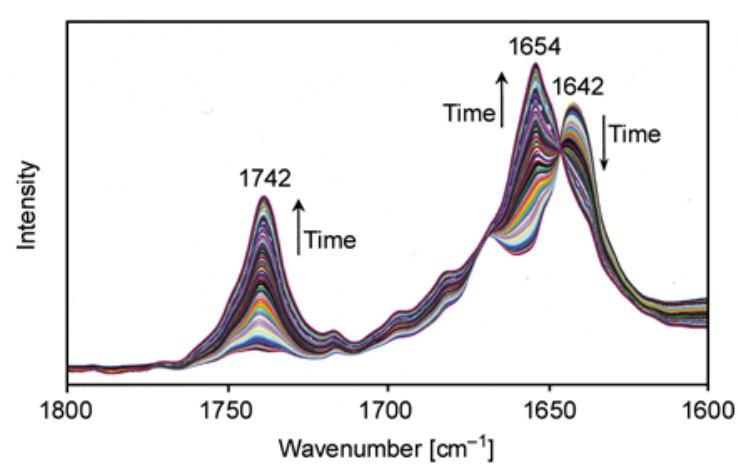

Figure 7. Absorbance FTIR spectra showing the evolution of the bands associated with the carboxylic ester group $\left(1742 \mathrm{~cm}^{-1}\right)$ and amide I $\left(1680-1620 \mathrm{~cm}^{-1}\right)$ during isothermal polymerizations of themomomer/C30B mixture at $110^{\circ} \mathrm{C}$

ance of a $\mathrm{C}=\mathrm{O}$ absorption band at $1742 \mathrm{~cm}^{-1}$, which is associated with the ester bond formed during polycondensation and a change in the wavenumber of the amide I absorption band (Figure 7). The latter should be found in both monomer and polymer samples but the different intermolecular hydrogen bond interactions should lead to a variation in the peak position and corresponding intensity.

Absorbance measurements of the above peaks during isothermal polymerizations were used (Equation (1)) to evaluate the relative conversion degree, $\alpha(t)$, for a given reaction time, $t$ :

$$
\alpha(t)=\frac{A_{\mathrm{t}}-A_{0}}{A_{\infty}-A_{0}}
$$

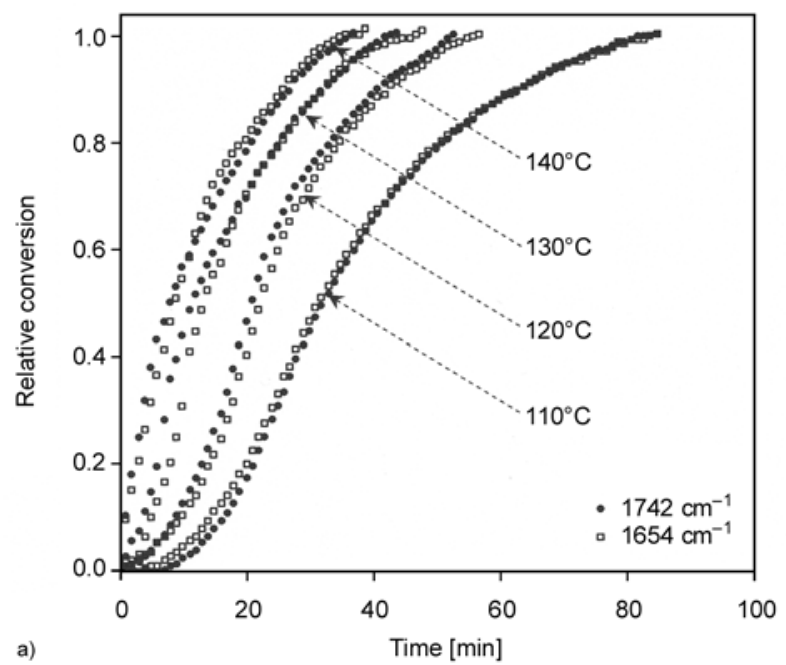

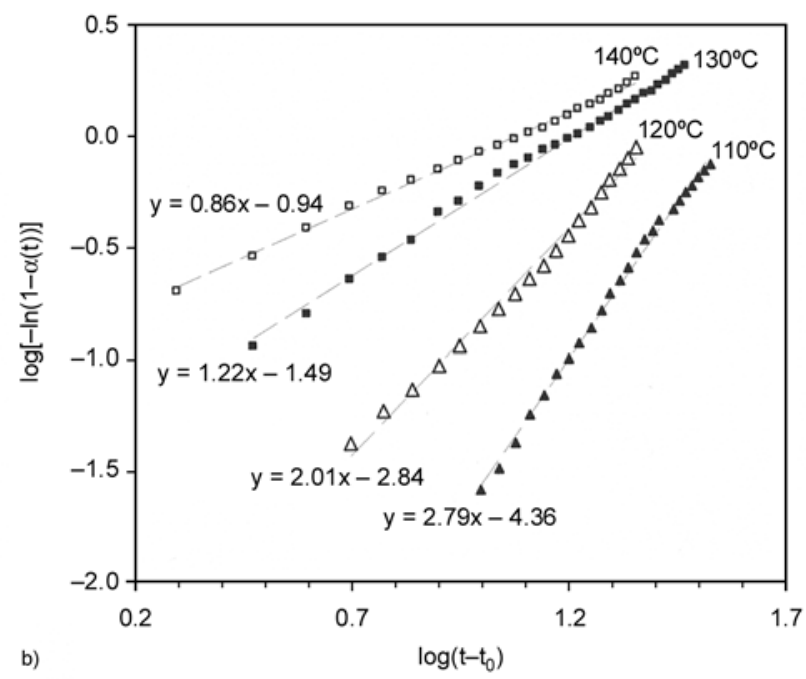

Figure 8. a) Plots of conversion versus reaction time for the isothermal polymerization of the momomer/C20A mixture at $140,130,120$ and $110^{\circ} \mathrm{C}$. Conversions were determined by absorbance measurements of 1742 and $1654 \mathrm{~cm}^{-1}$ FTIR peaks during the reaction process. b) Avrami plots for the polymerizations of the momomer/C20A mixture at the indicated temperatures. 
where $A_{\mathrm{t}}$ is the absorbance at time $t$, and $A_{\infty}$ and $A_{0}$ are, respectively, the final and initial absorbances.

Figure 8a compares the time evolution of the bands at 1742 and $1654 \mathrm{~cm}^{-1}$ for polymerizations carried out at different temperatures and in the presence of the C20A clay. For a given clay the evolution of the two bands is quite similar although slight differences were found when polymerization was performed at higher temperatures (i.e. at higher polymerization rates). As will be explained, the addition of clay particles and even their nature had an influence on the polymerization kinetics.

The $1742 \mathrm{~cm}^{-1}$ band was selected to perform a polymerization kinetic analysis since it seemed capable of rendering the most accurate data since it is not overlapped with other bands. The Avrami model was considered to examine the polymerization kinetics as it was previously applied for in situ polymerization using $\mathrm{C} 25 \mathrm{~A}$ clay and other similar systems $[21,27,30]$. This is a rough approximation that makes unnecessary a detailed study of the kinetic model but can provide useful values for comparison purposes. Conversion was then calculated by Equation (2):

$$
\alpha(t)=1-\exp \left(-Z\left(t-t_{0}\right)^{\mathrm{n}}\right)
$$

where $Z$ and $n$ are the corresponding Avrami parameters and $t_{0}$ the time at which polymerization starts. Plots of $\log [-\ln (1-\alpha(t))]$ versus $\log t$ at different reaction temperatures gave straight lines with slopes corresponding to the Avrami exponent, $n$, and their intercepts at the origin to $\log Z$ (e.g. Figure $8 b$ for polymerizations carried outwith C20A). Moreover, a kinetic constant $(k)$ with units independent of the Avrami exponent was calculated from $Z^{1 / n}$. These parameters are summarized in Table 1 for the two studied systems and the four assayed temperatures, together with the reciprocal of half conversion times $\left(\tau_{1 / 2}\right)$. Note that these times could be easily estimated from the conversion curves, and consequently without assuming a specific kinetic model. As expected, the kinetic constant increased with the polymerization temperature and evolved similarly to the reciprocal of the half polymerization time, $1 / \tau_{1 / 2}$, as shown in Figure $9 \mathrm{a}$ for the polymerization with C20A. This good agreement is relevant since the Avrami analysis results are corroborated by direct experimental measurements such as half polymerization times.

For comparative purposes, Table 1 also includes previous data on the polymerization of the neat monomer and its mixture with C25A (3 wt \%) [27]. It is clear that the overall rate kinetic constant of these two samples increased drastically with increasing temperature whereas a moderate change was observed for polymerizations carried out with $\mathrm{C} 20 \mathrm{~A}$ and $\mathrm{C} 30 \mathrm{~B}$. In this way, the neat monomer had a lower and higher polymerization rate than the $\mathrm{C} 20 \mathrm{~A}$ and $\mathrm{C} 30 \mathrm{~B}$ mixtures at 110 and $140^{\circ} \mathrm{C}$, respectively. The influence of temperature on the conversion degree is shown in Figure 9b, where simulated curves from Avrami parameters are plotted for all samples at the intermediate temperatures of 130 and $120^{\circ} \mathrm{C}$. It is worth pointing out that the neat monomer

Table 1. Polymerization kinetic parameters deduced from FTIR absorbance measurements of the $1742 \mathrm{~cm}^{-1}$ band

\begin{tabular}{|c|c|c|c|c|c|}
\hline & $\mathbf{T}\left[{ }^{\circ} \mathrm{C}\right]$ & $1 / \tau_{1 / 2}\left[\min ^{-1}\right]$ & $\mathrm{Z}\left[\mathrm{min}^{-\mathrm{n}}\right]$ & $\mathbf{n}$ & $\mathrm{k}\left[\mathrm{min}^{-1}\right]$ \\
\hline Monomer/C20A mixture & 110 & 0.033 & $4.00 \cdot 10^{-5}$ & 2.79 & 0.027 \\
\hline Monomer/C20A mixture & 120 & 0.049 & $1.43 \cdot 10^{-3}$ & 2.01 & 0.038 \\
\hline Monomer/C20A mixture & 130 & 0.087 & $3.20 \cdot 10^{-2}$ & 1.22 & 0.060 \\
\hline Monomer/C20A mixture & 140 & 0.120 & $1.11 \cdot 10^{-1}$ & 0.86 & 0.081 \\
\hline Monomer/C30B mixture & 110 & 0.033 & $3.89 \cdot 10^{-3}$ & 1.51 & 0.025 \\
\hline Monomer/C30B mixture & 120 & 0.050 & $3.18 \cdot 10^{-3}$ & 1.76 & 0.038 \\
\hline Monomer/C30B mixture & 130 & 0.083 & $3.89 \cdot 10^{-3}$ & 1.98 & 0.060 \\
\hline Monomer/C30B mixture & 140 & 0.134 & $7.19 \cdot 10^{-2}$ & 1.14 & 0.098 \\
\hline Monomer/C25A mixture $^{a}$ & 100 & 0.010 & $1.12 \cdot 10^{-4}$ & 1.80 & 0.006 \\
\hline Monomer/C25A mixture $^{a}$ & 120 & 0.036 & $1.02 \cdot 10^{-2}$ & 1.31 & 0.030 \\
\hline Monomer/C25A mixture $^{a}$ & 130 & 0.060 & $1.51 \cdot 10^{-2}$ & 1.42 & 0.052 \\
\hline Monomer/C25A mixture ${ }^{\mathrm{a}}$ & 140 & 0.142 & $1.82 \cdot 10^{-1}$ & 0.93 & 0.158 \\
\hline Neat monomer ${ }^{\mathrm{a}}$ & 100 & 0.011 & $5.01 \cdot 10^{-4}$ & 1.59 & 0.008 \\
\hline Neat monomer ${ }^{\mathrm{a}}$ & 120 & 0.042 & $7.41 \cdot 10^{-3}$ & 1.50 & 0.038 \\
\hline Neat monomer ${ }^{\mathrm{a}}$ & 130 & 0.128 & $7.58 \cdot 10^{-2}$ & 1.22 & 0.120 \\
\hline Neat monomer ${ }^{\mathrm{a}}$ & 140 & 0.200 & $2.29 \cdot 10^{-1}$ & 0.87 & 0.185 \\
\hline
\end{tabular}

${ }^{a}$ Data from reference [27] 

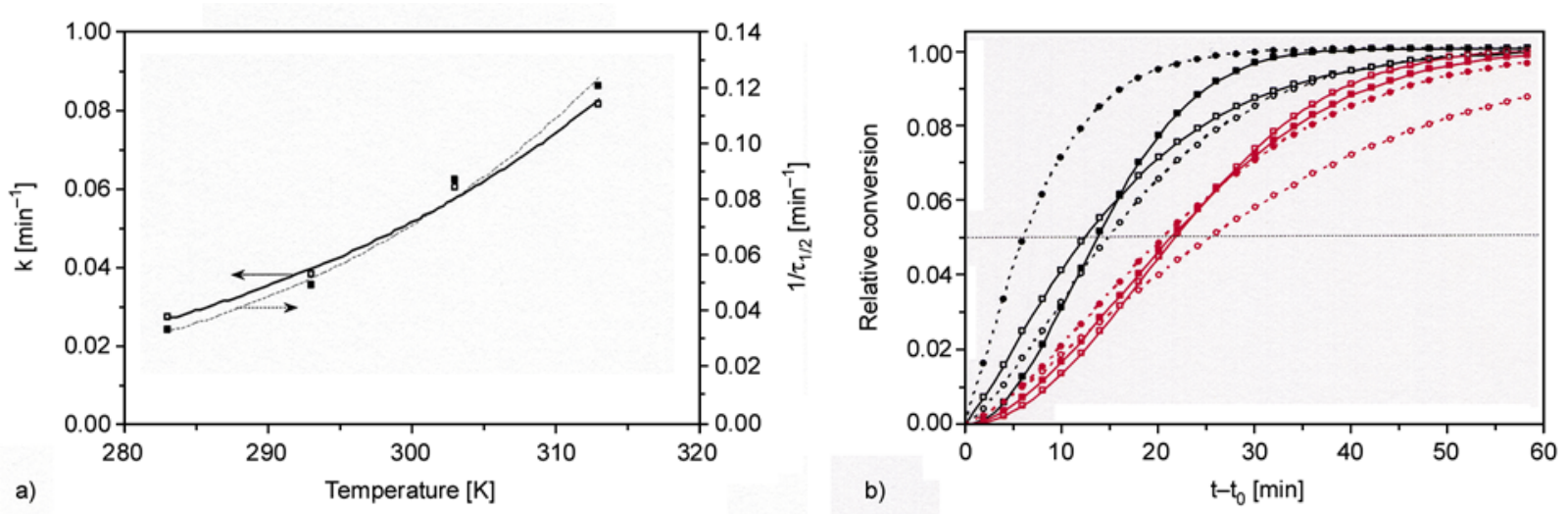

Figure 9. a) Comparison between the kinetic polymerization constant (solid line) and the reciprocal of the half polymerization time (dashed line) determined at different isothermal polymerization temperatures for the momomer/C20A mixture. b) Comparison of the conversion evolution between the neat monomer $(\cdot$, dashed line), the monomer / C25A mixture ( $\circ$, dashed line), the monomer / C20A mixture ( $\square$, solid line) and the monomer/C30B mixture ( $\mathbf{m}$, solid line) at the isothermal polymerization temperature of $130^{\circ} \mathrm{C}$ (black lines) and $120^{\circ} \mathrm{C}$ (red lines). Data were calculated using Equation (2) and the corresponding Avrami parameters (Table 2 and Reference [27]).

has the fastest conversion at $130^{\circ} \mathrm{C}$ but its polymerization rate becomes comparable with that found for the $\mathrm{C} 20 \mathrm{~A}$ and $\mathrm{C} 30 \mathrm{~B}$ mixtures when the temperature decreased to $120^{\circ} \mathrm{C}$. Comparison data clearly demonstrated that clay particles influenced the polymerization rate and that the effect of clays that rendered a predominant intercalated structure $(\mathrm{C} 20 \mathrm{~A}$ and $\mathrm{C} 30 \mathrm{~B}$ ) and $\mathrm{C} 25 \mathrm{~A}$ clay, which gave rise to an exfoliated structure, was different.

The polymerization activation energies of the mixtures between the neat monomer and $\mathrm{C} 20 \mathrm{~A}$ and C30B clays were derived by assuming an Arrhenius-type temperature dependence of the kinetic constant (Equation (3)), where $E, A$ and $R$ are the activation energy, the preexponential frequency factor and the universal gas constant, respectively:

$k=A \exp \left(-\frac{E}{R T}\right)$

Plots of $\ln k$ versus $1 / T$ (Figure 10) allowed activation energies of 49.4 and $59.8 \mathrm{~kJ} / \mathrm{mol}$ to be deduced for in situ polymerization of $\mathrm{C} 20 \mathrm{~A}$ and $\mathrm{C} 30 \mathrm{~B}$ mixtures, respectively. These energies were practically identical, but differed significantly from the value previously deduced for the neat monomer $(101.0 \mathrm{~kJ} / \mathrm{mol})$ and even for its $\mathrm{C} 25 \mathrm{~A}$ mixture $(99.3 \mathrm{~kJ} / \mathrm{mol})$, which gave rise to an exfoliated structure [27]. In this way, the activation energy clearly decreased when in situ polymerization rendered an intercalated structure. The preexponential frequency factor was also lower for the nanocomposites than for the neat monomer $\left(3.28 \cdot 10^{12} \mathrm{~min}^{-1}\right)$, indicating

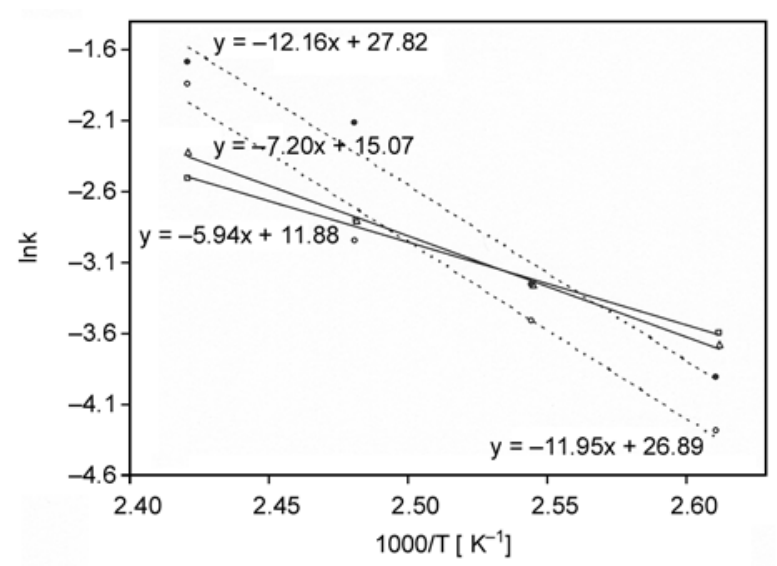

Figure 10. Plots of $\ln k$ versus the reciprocal of the polymerization temperature for the neat monomer $(\bullet$, dashed line) [27] and monomer/C25A (○, dashed line) [27], momomer/C20A ( $\square$, solid line) and monomer/C30B $(\Delta$, solid line $)$ mixtures

that chain mobility was restricted by the incorporation of clay particles. Both C20A and C30B clays led to frequency factors of a similar magnitude order $\left(1.4 \cdot 10^{5}\right.$ and $3.4 \cdot 10^{6} \mathrm{~min}^{-1}$, respectively), but significantly lower than that found for the C25A mixture $\left(4.77 \cdot 10^{11} \mathrm{~min}^{-1}\right)$.

The polymerization kinetics of monomer/C20A and monomer/C30B mixtures was enhanced at low temperatures due to their low activation energy, which compensated for the decrease caused by their low frequency factor. On the contrary, this factor was determinant at high temperatures, where the corresponding overall rate kinetic constants became minimal. 
The changes observed in the activation energy and frequency factor may suggest that nanoconfinement in intercalated structures favored the polycondensation reaction and reduced molecular mobility. It should be emphasized that activation energy did not decrease when nanoconfinement was loosened (i.e. when an exfoliated structure was attained). In this case, the exfoliated layers hindered the chain mobility and reduced again the frequency factor of the condensation reaction.

\subsection{Isothermal crystallization kinetics of poly (glc-alt-amh) and its $\mathrm{C2OA}$ and $\mathrm{C30B}$ nanocomposites from FTIR analyses}

FTIR is highly sensitive to molecular conformation and packing density, hence its usefulness in polymer crystallization studies. Characteristic bands can

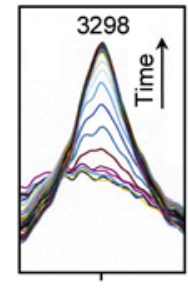

3300

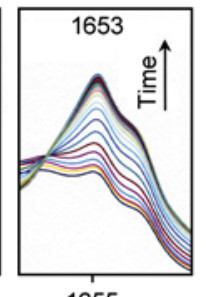

Wavenumber $\left[\mathrm{cm}^{-1}\right]$

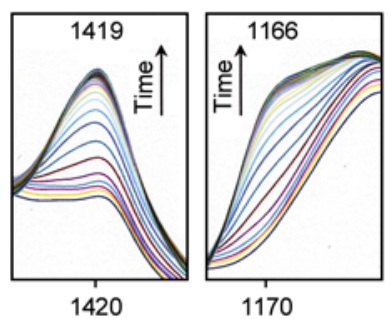

a)

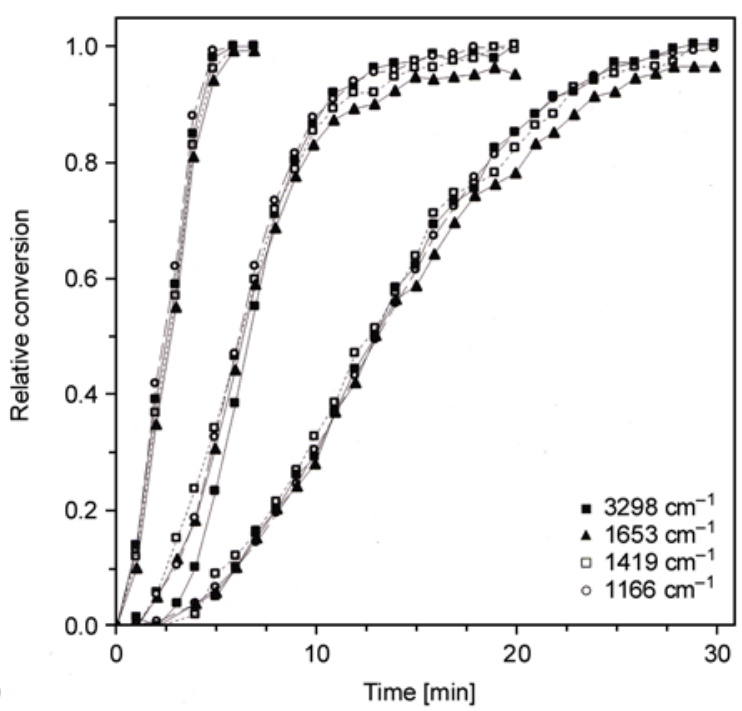

Figure 11. a) Changes in the infrared absorption bands at $3298,1653,1419$ and $1166 \mathrm{~cm}^{-1}$ of the poly $(\mathrm{glc}-$ alt-amh)/C20A nanocomposite during isothermal crystallization at $135^{\circ} \mathrm{C}$. b) Time evolution of the relative crystallinity determined from absorbance measurements of the $3298(\mathbf{a})$, $1653(\mathbf{\Delta}), 1419$ (口) and $1166(\circ) \mathrm{cm}^{-1}$ FTIR bands of the poly(glc-alt-amh)/C30B nanocomposite during isothermal crystallization at $135^{\circ} \mathrm{C}$. be correlated to the crystalline and amorphous phases of the bulk and typically remain distinguishable over the course of crystallization. Isothermal studies are preferred to avoid shape and intensity susceptibility of FTIR bands with temperature.

FTIR spectra of poly (glc-alt-amh) showed that $3298,1653,1419$ and $1166 \mathrm{~cm}^{-1}$ bandswere characteristic of the crystalline phase. Thus, these bands appeared and their absorbance gradually increased during the isothermal crystallization of samples rapidly cooled to the selected temperature from the melt (amorphous) state.

The continuous evolution of these absorption bands is shown in Figure 11a for the C20A nanocomposite at a representative crystallization temperature of $135^{\circ} \mathrm{C}$. The time evolution of the relative degree of crystallization, $\chi(t)$, was evaluated similarly to that of the degree of conversion (i.e. changing $\alpha(t)$ by $\chi(t)$ in Equations (1) and (2)). Figure 11b shows that the four selected bands exhibit a similar behavior for a given crystallization temperature. Thus, in all cases the maximum crystallinity change was detected at a similar time. However, absorbance measurements seemed more accurate when the signal corresponding to the Amide A $\left(3298 \mathrm{~cm}^{-1}\right)$ was considered. The establishment of stronger hydrogen bond interactions in the crystalline structure gave rise to a well defined band which, in addition, was not overlapped by other peaks.

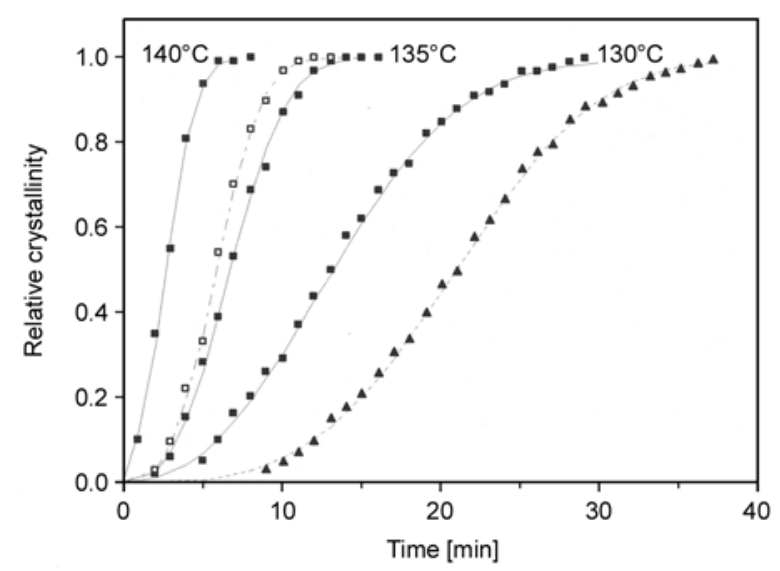

Figure 12. Time evolution of the relative crystallinity determined from absorbance measurements of the $3298 \mathrm{~cm}^{-1}$ FTIR band of the poly(glc-alt-amh)/ C30B nanocomposite (匹) during isothermal crystallization at 140,135 and $130^{\circ} \mathrm{C}$. For comparative purposes, the evolution for the poly (glc-alt-amh)/C20A nanocomposite ( $\square$, dashed line) and the neat polymer at $135^{\circ} \mathrm{C}$ is also shown ( $\boldsymbol{\Delta}$, dashed line). 


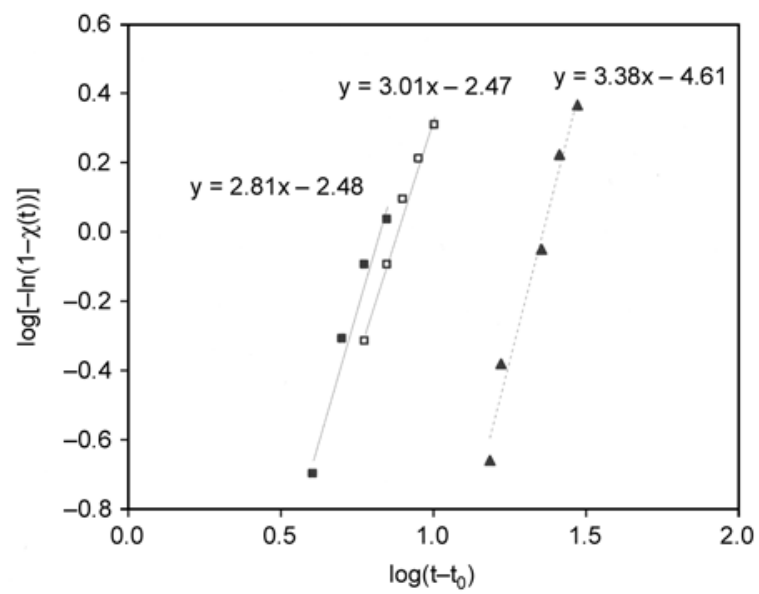

Figure 13. Avrami plot considering FTIR data $\left(3298 \mathrm{~cm}^{-1}\right.$ band) for isothermal crystallization of the neat poly(ester amide) ( $\boldsymbol{\Delta}$ ) and its C20A ( $\square$ ) and $\mathrm{C} 30 \mathrm{~B}(\mathbf{m})$ nanocomposites at $135^{\circ} \mathrm{C}$

Table 2. Crystallization kinetic parameters at $135^{\circ} \mathrm{C}$ deduced from FTIR absorbance measures of the $3298 \mathrm{~cm}^{-1}$ band

\begin{tabular}{|l|c|c|c|c|}
\hline \multicolumn{1}{|c|}{ Sample } & $\begin{array}{c}\mathbf{1} / \boldsymbol{\tau}_{\mathbf{1}} \mathbf{2} \\
{\left[\mathbf{m i n}^{-\mathbf{1}}\right]}\end{array}$ & $\begin{array}{c}\mathbf{Z} \\
{\left[\mathbf{m i n}^{-\mathbf{n}}\right]}\end{array}$ & $\mathbf{n}$ & $\begin{array}{c}\mathbf{k} \\
{\left[\mathbf{m i n}^{-\mathbf{1}}\right]}\end{array}$ \\
\hline Neat polymer & 0.048 & $2.40 \cdot 10^{-5}$ & 3.38 & 0.043 \\
\hline Nanocomposite with C20A & 0.174 & $3.40 \cdot 10^{-3}$ & 3.01 & 0.153 \\
\hline Nanocomposite with C30B & 0.149 & $3.28 \cdot 10^{-3}$ & 2.81 & 0.131 \\
\hline
\end{tabular}

Figure 12 compares the evolution of the degree of crystallinity at different temperatures for the $\mathrm{C} 30 \mathrm{~B}$ nanocomposite, as well as the evolution of the neat polymer and its $\mathrm{C} 30 \mathrm{~B}$ and $\mathrm{C} 20 \mathrm{~A}$ nanocomposites at a representative temperature $\left(135^{\circ} \mathrm{C}\right)$. Note that the crystallization rate is clearly slower for the neat polymer.

Avrami plots (as shown in Figure 13 for the C30B nanocomposite) allowed determining an exponent close to 3, which is the theoretical value for heterogeneous nucleation and three-dimensional spherulitic growth. In the same way, the kinetic constant, $k$, was calculated from the deduced $Z$ and $\mathrm{n}$ values. Table 2 compares the kinetic parameters of the three studied samples at a common temperature $\left(135^{\circ} \mathrm{C}\right)$. The Avrami exponents of the three samples were close enough to deduce that nucleation type and crystal dimensionality remained unaffected by the addition of clay particles. On the contrary, the incorporation of silicate layers with an intercalated structure clearly increased the overall rate kinetic constant. This effect was more pronounced with C20A clay, as shown in Table 2. Note that the same trend was observed when the reciprocal of the half crystallization time, $1 / \tau_{1 / 2}$, was con-
sidered.This good correlation with a direct experimental measurement may validate the Avrami analysis of the crystallization process.

\subsection{Optical microscopy studies on the isothermal crystallization of poly(glc-alt-amh) and its $\mathrm{C20A}$ and $\mathrm{C30B}$ nanocomposites}

The spherulites of the neat poly(ester amide) and its C20A and C30B nanocomposites had negative birefringence, as demonstrated by the position of the blue and yellow arms in the optical micrographs in the inset of Figure 14. Different spherulitic morphologies were observed depending on the crystallization temperature and the addition of clay particles. Thus, the neat polymer gave rise to speckled, ringed and fibrilar spherulites at temperatures close to 125,130 and $140^{\circ} \mathrm{C}$, respectively. The addition of a clay that rendered an exfoliated structure (i.e. C25A) favored the development of fibrilar textures [27] and hindered lamellar twisting, whereas the incorporation of clays associated with a final intercalated structure (i.e. C20A and C30B) led to the formation of speckled textures, as shown in Figure 14.

Nucleation density was higher for the nanocomposites derived from $\mathrm{C} 20 \mathrm{~A}$ and $\mathrm{C} 30 \mathrm{~B}$ (i.e. those with an intercalated structure), as deduced from the number of spherulites measured in the field of view of the optical microscope. At all temperatures, the nucleation density decreased in the order $\mathrm{C} 20 \mathrm{~A}>$ $\mathrm{C} 30 \mathrm{~B}>$ neat polymer, as shown in Figure 15a.

The change in the primary nucleation was responsible for the difference in overall crystallization rates between the neat polymer and C20A and C30B nanocomposites found by FTIR. The incorporation of a clay that favors an intercalated structure increased the nucleation density. In fact, the experimental data indicate that the effect was more pronounced with the addition of C20A clay. It should be pointed out that the crystallization of the C25A nanocomposite was previously studied and that a lower nucleation density was derived for this sample with an exfoliated silicate structure [27]. Furthermore, the overall crystallization rate decreased when this clay was incorporated.

The spherulic radial growth rates $(G)$ of the neat sample and its $\mathrm{C} 20 \mathrm{~A}$ and $\mathrm{C} 30 \mathrm{~B}$ nanocomposites were determined with the evolution of the spherulite 


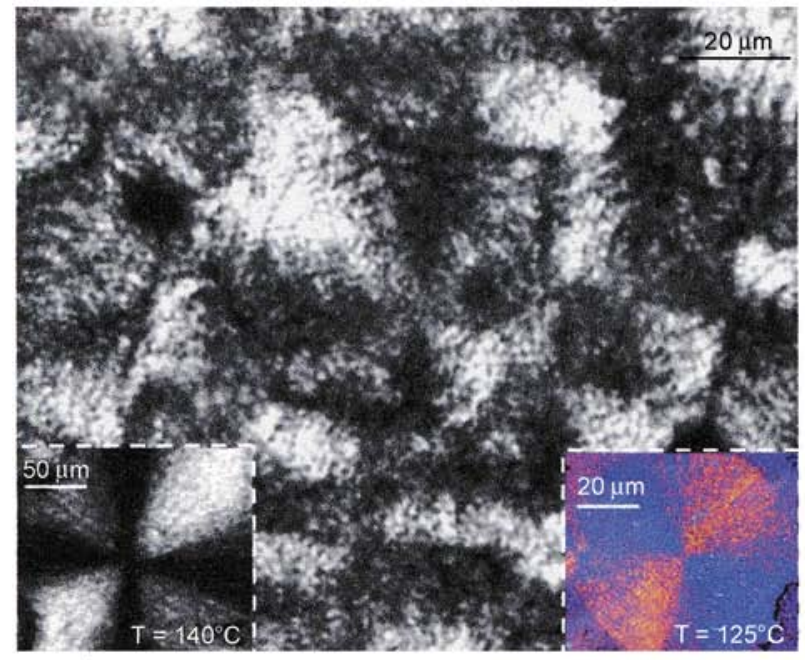

a)

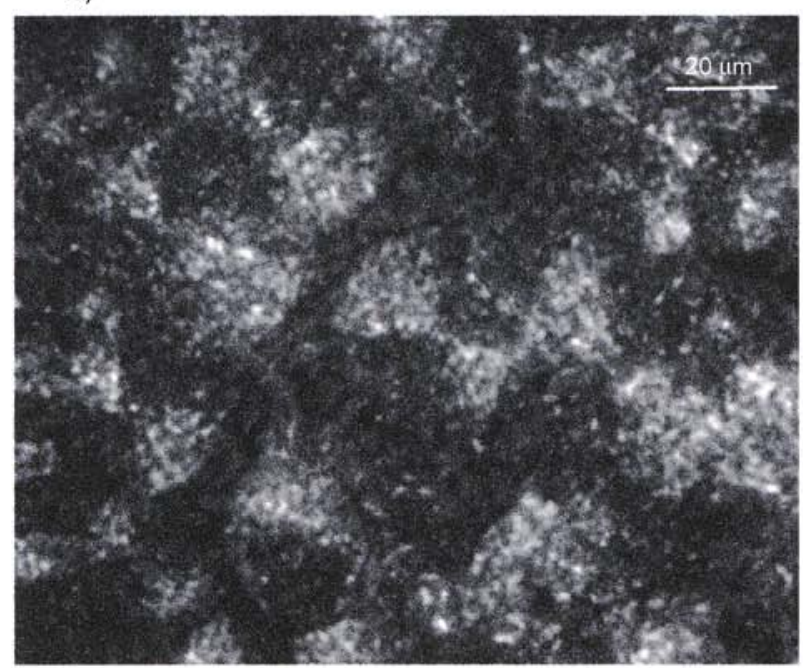

c)

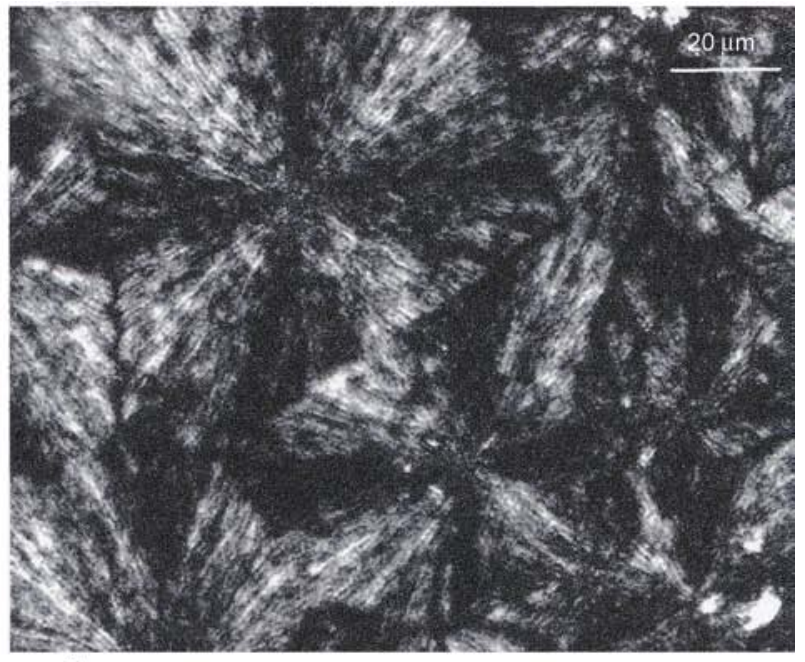

b)

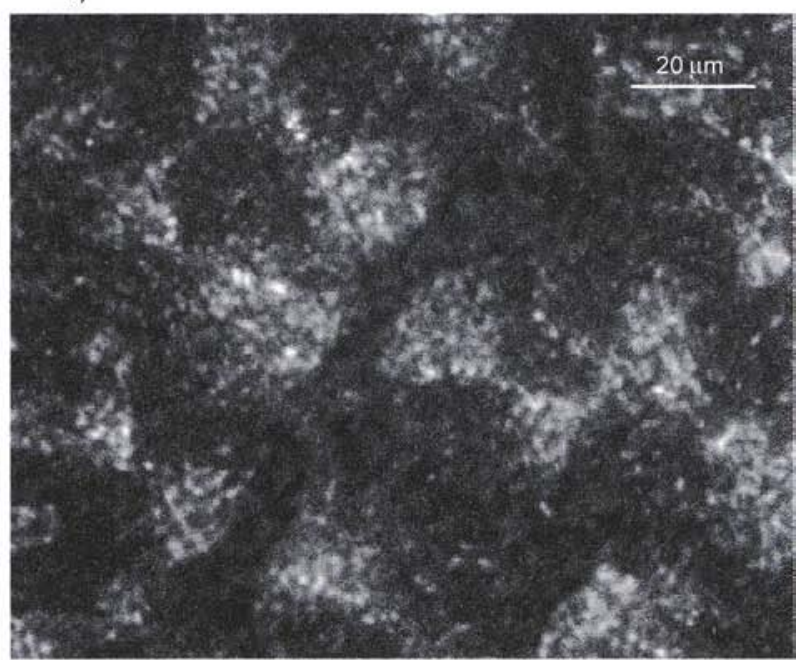

d)

Figure 14. Polarized optical micrographs showing the isothermal hot crystallizations of the neat poly(ester amide) (a) and its $\mathrm{C} 25 \mathrm{~A}(\mathrm{~b}), \mathrm{C} 20 \mathrm{~A}(\mathrm{c})$ and $\mathrm{C} 30 \mathrm{~B}(\mathrm{~d})$ nanocomposites at $130^{\circ} \mathrm{C}$. Insets show micrographs of speckled and fibrilar spherulites attained at 125 and $140^{\circ} \mathrm{C}$, respectively, with the neat polymer sample.
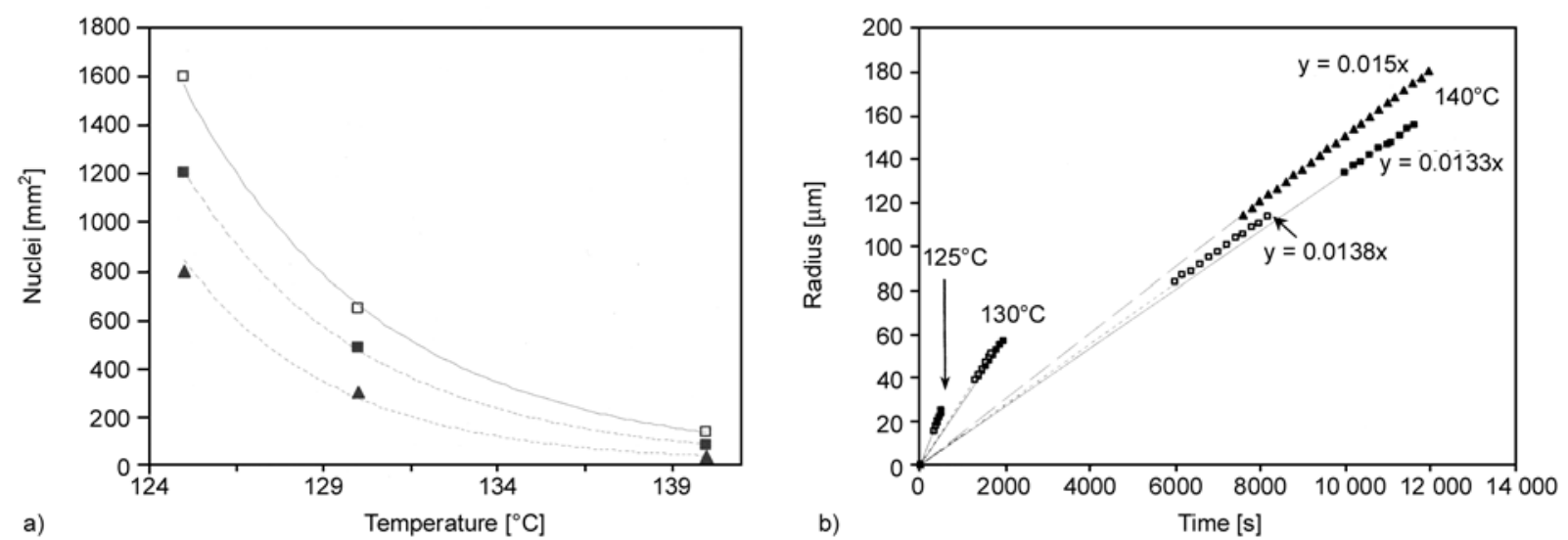

Figure 15. a) Variation in nucleation density with isothermal crystallization temperature for the neat polymer $(\boldsymbol{\Delta})$ and its C20A ( $\square$ ) and C30B ( $\mathbf{a})$ nanocomposites. b) Plot of the radius of spherulites of the neat polymer $(\boldsymbol{\Delta})$ and its C20A ( $\square$ ) and C30B nanocomposites ( $\mathbf{a})$ versus crystallization time for isothermal crystallizations at 125, 130 and $140^{\circ} \mathrm{C}$. 
radius versus time. It is worth pointing out that a linear increase in the spherulite radius was always found, suggesting that clay particles were not segregated during spherulite growth. Data for crystallization temperatures of 125,130 and $140^{\circ} \mathrm{C}$ (Figure $15 \mathrm{~b}$ ) showed that the growth rate of the two nanocomposites was similar although a slightly lower value was found for C30B. Differences were more significant at a high crystallization temperature (e.g. $\left.140^{\circ} \mathrm{C}\right)$, with measurements clearly indicating that the incorporation of clay particles reduced the spherulitic growth rate (i.e. $0.015 \mu \mathrm{m} / \mathrm{s}$ versus $0.014-0.013 \mu \mathrm{m} / \mathrm{s}$ ). Note that the overall crystallization process did not decelerate with the addition of clay particles since the accelerative effect caused by the increase in the primary nucleation density was more significant than the decrease in the crystal growth rate.

In summary, silicate particles acted as effective nucleating agents at low degrees of compatibility, a result that contrasts with the observations on the exfoliated structure (i.e. when the organo-modified clay becomes highly miscible with the polymer matrix) which indicated a decrease on the primary nucleation. In all cases, the addition of clay particles slightly reduced the radial growth rate since both secondary nucleation and molecular transport may be influenced by the presence of nanoparticles.

\section{Conclusions}

Nanocomposites constituted by a poly(ester amide) matrix and $\mathrm{C} 20 \mathrm{~A}$ or $\mathrm{C} 30 \mathrm{~B}$ organo-modified clays were obtained by in situ polymerization of sodium chloroacetylaminohexanoate. They showed an intercalated silicate structure, as determined by Xray diffraction and transmission electron microscopy. The polymerization kinetics under both non-isothermal and isothermal conditions was quite similar after the incorporation of the two clays. However, great differences were found with the polymerization of the neat monomer. The temperature dependence of the polymerization kinetic constant allowed inferring the activation energies and preexponential frequency factors, which were lower when polymerization was performed in the presence of clay particles. Nanoconfinement in the intercalated silicate galleries may favor the occurrence of polycon- densation reactions and reduce the corresponding activation energy. This confinement should logically result in decreased chain mobility and consequently lower frequency factor.

Optical microscopy and FTIR studies revealed that the crystallization rate of the nanocomposites increased due to the nucleation effect of clay particles. On the contrary, spherulitic crystal growth was slightly hindered when particles were added. Spherulites always showed negative birefringence but their texture was influenced by the incorporation of clay and obviously by the crystallization temperature.

\section{Acknowledgements}

This research has been supported by grants from MICYT/ FEDER and AGAUR (MAT2009-11503, 2009SGR-1208). We want to express our gratitude to Drs. François Fauth and Ana Labrador of the CRG BM16 beamline staff of CELLS (Consortium for the Exploitation of the Synchrotron Light Laboratory).

\section{References}

[1] Pavlidou S., Papaspyrides C. D.: A review on polymer-layered silicate nanocomposites. Progress in Polymer Science, 12, 1119-1198 (2008).

DOI: 10.1016/j.progpolymsci.2008.07.008

[2] Ray S. S., Bousmina M.: Biodegradable polymers and their layered silicate nanocomposites: In greening the $21^{\text {st }}$ century materials world. Progress in Materials Science, 50, 962-1079 (2005).

DOI: $10.1016 /$ j.pmatsci.2005.05.002

[3] Ray S. S., Okamoto M.: Polymer/layered silicate nanocomposites: A review from preparation to processing. Progress in Polymer Science, 28, 1539-1641 (2003).

DOI: $10.1016 /$ j.progpolymsci.2003.08.002

[4] Carrado K. A.: Synthetic organo- and polymer-clays: Preparation, characterization and materials applications. Applied Clay Science, 17, 1-23 (2000). DOI: $10.1016 / \mathrm{S} 0169-1317(00) 00005-3$

[5] Alexandre M., Dubois P.: Polymer-layered silicate nanocomposites: Preparation, properties and uses of a new class of materials. Materials Science and Engineering R: Reports, 28, 1-63 (2000). DOI: 10.1016/S0927-796X(00)00012-7

[6] Usuki A., Kojima Y., Kawasumi M., Okada A., Fukushima Y., Kurauchi T., Kamigato O.: Synthesis of nylon 6-clay hybrid. Journal of Materials Research, 8, 1179-1184 (1993). DOI: $\underline{10.1557 / J M R .1993 .1179}$ 
[7] Kawasumi M.: The discovery of polymer-clay hybrids. Journal Polymer Science Part A: Polymer Chemistry, 42, 819-824 (2004).

DOI: $10.1002 /$ pola.10961

[8] Ishida H., Campbell S., Blackwell J.: General approach to nanocomposite preparation. Chemistry of Materials, 12, 1260-1267 (2000). DOI: $10.1021 / \mathrm{cm} 990479 y$

[9] Akelah A., Salahuddin N., Hiltner A., Baer E., Moet A.: Morphological hierarchy of butadieneacrylonitrile/montmorillonite nanocomposite. Nanostructured Materials, 4, 965-978 (1994). DOI: 10.1016/0965-9773(94)90103-1

[10] Kennedy M. A., Brown G. R., St-Pierre L. E.: Crystallization of isotactic $(\mathrm{D}, \mathrm{L})$ poly(propylene oxide) in the presence of fine-particle silica. I: Radial growth rates of spherulites. Polymer Engineering and Science, 30, 769-775 (1990).

DOI: $10.1002 /$ pen.760301304

[11] Nitta K-H., Asuka K., Liu B. P., Terano M.: The effect of the addition of silica particles on linear spherulite growth rate of isotactic polypropylene and its explanation by lamellar cluster model. Polymer, 47, 64576463 (2006).

DOI: $10.1016 /$ j.polymer.2006.06.054

[12] Somwangthanaroj A., Lee E. C., Solomon M. J.: Early stage quiescent and flow-induced crystallization of intercalated polypropylene nanocomposites by timeresolved light scattering. Macromolecules, 36, 2333 2342 (2003).

DOI: $10.1021 / \mathrm{ma} 021454 \mathrm{e}$

[13] Nowacki R., Monasse B., Piorkowska E., Galeski A., Haudin J. M.: Spherulite nucleation in isotactic polypropylene based nanocomposites with montmorillonite under shear. Polymer, 45, 4877-4892 (2004). DOI: 10.1016/j.polymer.2004.04.058

[14] Burke M., Young R. J., Stanford J. L.: The relationship between structure and properties in titanium dioxide filled polypropylene. Polymer Bulletin, 30, 361-368 (1993). DOI: $10.1007 / \mathrm{BF} 00343073$

[15] Stapert H. R., Bouwens A. W., Dijkstra P. J., Feijen J.: Environmentally degradable aliphatic poly(esteramide)s based on short, symmetrical and uniform bisamide-diol blocks, 1 . Synthesis and interchange reactions. Macromolecular Chemistry and Physics, 200, 1921-1929 (1999).

DOI: $10.1002 /($ SICI)1521-3935(19990801)200:8<1921 $\because$ AID-MACP1921>3.0.CO;2-R

[16] Guo K., Chu C. C.: Synthesis, characterization, and biodegradation of copolymers of unsaturated and saturated poly(ester amide)s. Jounal of Polymer Science Part A: Polymer Chemistry, 45, 1595-1606 (2007). DOI: $10.1002 /$ pola.21926
[17] Paredes N., Rodríguez-Galán A., Puiggali J.: Synthesis and characterization of a family of biodegradable poly (ester amide)s derived from glycine. Journal of Polymer Science Part A: Polymer Chemistry, 36, 12711282 (1998).

DOI: 10.1002/(SICI)1099-0518(199806)36:8<1271:: AID-POLA10>3.3.CO;2-U

[18] Guo K., Chu C. C.: Synthesis, characterization, and biodegradation of novel poly(ether ester amide)s based on L-phenylalanine and oligoethylene glycol. Biomacromolecules, 8, 2851-2861 (2007).

DOI: $10.1021 / \mathrm{bm} 070158 \mathrm{c}$

[19] Rodríguez-Galán A., Pelfort M., Aceituno J. E., Puiggalí J.: Comparative studies on the degradability of poly(ester amide)s derived from L- and L,D-alanine. Journal of Applied Polymer Science, 74, 2312-2320 (1999).

DOI: 10.1002/(SICI)1097-4628(19991128)74:9<2312:: AID-APP21>3.0.CO;2-0

[20] Vera M., Rodríguez-Galán A., Puiggali J.: New method of synthesis of poly(ester amide)s derived from the incorporation of glycolic acid residues into aliphatic polyamides. Macromolecular Rapid Communications, 25, 812-817 (2004).

DOI: $10.1002 /$ marc. 200300273

[21] Vera M., Franco L., Puiggalí J.: Synthesis and characterization of poly(glycolic acid-alt-6-aminohexanoic acid) and poly(glycolic acid-alt-11-aminoundecanoic acid). Macromolecular Chemistry and Physics, 205, 1782-1792 (2004).

DOI: $10.1002 / \mathrm{macp} .200400191$

[22] Wang D., Zhu J., Yao Q., Wilkie C. A.: A comparison of various methods for the preparation of polystyrene and poly(methyl methacrylate) clay nanocomposites. Chemistry of Materials, 14, 3837-3843 (2002). DOI: $10.1021 / \mathrm{cm} 011656+$

[23] LeBaron P. C., Wang Z., Pinnavaia T. J.: Polymer-layered silicate nanocomposites: An overview. Applied Clay Science, 12, 11-29 (1999). DOI: $10.1016 / \mathrm{S} 0169-1317(99) 00017-4$

[24] Akelah A., Moet A.: Polymer-clay nanocomposites: Free-radical grafting of polystyrene on to organophilic montmorillonite interlayers. Journal of Materials Science, 31, 3589-3596 (1996).

DOI: $10.1007 / \mathrm{BF} 00360767$

[25] Messersmith P. B., Giannelis E. P.: Polymer-layered silicate nanocomposites: In situ intercalative polymerization of $\varepsilon$-caprolactone in layered silicates. Chemistry of Materials, 5, 1064-1066 (1993).

DOI: $10.1021 / \mathrm{cm} 00032 \mathrm{a} 005$

[26] Fukushima Y., Okada A., Kawasumi M., Kurauchi T., Kamigaito O.: Swelling behavior of montmorillonite by poly-6-amide. Clay Minerals, 23, 27-34 (1988). 
[27] Morales L., Franco L., Casas M. T., Puiggalí J.: Poly(ester amide)/clay nanocomposites prepared by in situ polymerization of the sodium salt of $\mathrm{N}$-chloroacetyl-6-aminohexanoic acid. Journal Polymer Science Part A: Polymer Chemistry, 47, 3616-3629 (2009).

DOI: $10.1002 /$ pola.23430

[28] Morales-Gámez L., Franco L., Casas M. T., Puiggalí J.: Crystallization studies on a clay nanocomposite prepared from a degradable poly(ester amide) constituted by glycolic acid and 6-aminohexanoic acid. Polymer Engineering and Science, in press (2011). DOI: $10.1002 /$ pen.21936
[29] Botines E., Casas M. T., Puiggalí J.: Alternating poly(ester amide)s of glycolic acid and $\omega$-amino acids: Crystalline morphology and main crystallographic data. Journal of Polymer Science Part B: Polymer Physics, 45, 815-825 (2007).

DOI: $10.1002 /$ polb.21077

[30] Rodríguez-Galán A., Vera M., Jiménez K., Franco L., Puiggalí J.: Synthesis of poly(ester amide)s derived from glycolic acid and the amino acids: $\beta$-alanine or 4aminobutyric acid. Macromolecular Chemistry and Physics, 204, 2078-2089 (2003).

DOI: $\underline{10.1002 / \mathrm{macp} .200350064}$ 